\title{
Hypersensitivity pneumonitis
}

INSERM

\section{Source}

INSERM. (1999). Orphanet: an online rare disease and orphan drug data base.

Hypersensitivity pneumonitis. ORPHA:31740

Hypersensitivity pneumonitis (HP) is a pulmonary disease with symptoms of dyspnea and cough resulting from the inhalation of an antigen to which the subject has been previously sensitized. 